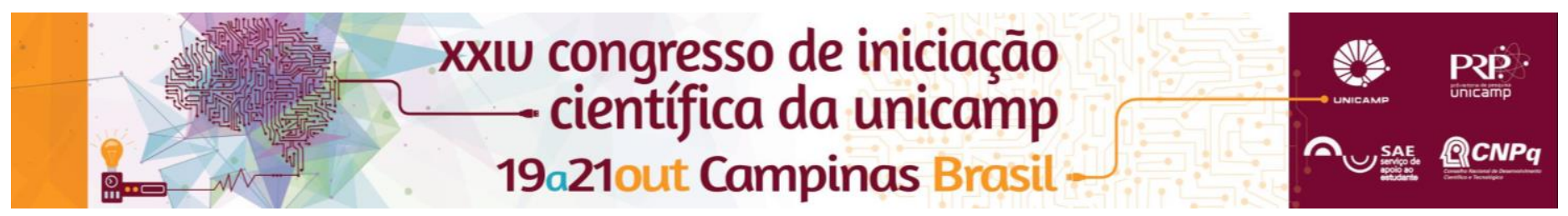

\title{
Comportamento de Estaca Tipo Escavada Submetida a Esforços Horizontais em Solo Poroso Não-Saturado
}

\author{
Gustavo Macedo da Cruz*, Prof. Dr. Paulo José Rocha Albuquerque, Mairon Miranda.
}

\begin{abstract}
Resumo
Nesta pesquisa, analisou-se o comportamento de uma estaca escavada de $5 \mathrm{~m}$ de comprimento e 0,30 m de diâmetro submetida ao carregamento horizontal, por meio da realização de prova de carga. A estaca foi executada no Campo Experimental de Mecânica dos Solos e Fundações da Faculdade de Engenharia Civil, Arquitetura e Urbanismo da Unicamp. Com base nos resultados do ensaio, foi possível determinar o coeficiente de reação horizontal através do método de Matlock \& Reese (1960, 1961), a capacidade de carga horizontal e a avaliação dos efeitos da inundação. Para isto, foram consideradas duas condições do solo, natural e inundado, a fim de constatar o efeito da inundação em solos colapsíveis.
\end{abstract}

\section{Palavras-chave:}

prova de carga horizontal, solo poroso, estaca escavada.

\section{Introdução}

Os esforços horizontais estão presentes em muitos tipos de fundações, podendo citar as fundações de pontes, torres de transmissão, arranha-céus, etc. Eles podem ser gerados pela ação do vento, empuxo exercido pela terra, ondas marítimas, frenagem e arrancada de automóveis e atividade sísmica.

A prova de carga horizontal foi realizada com uma estaca escavada a trado mecânico, de diâmetro nominal de 0,30 $\mathrm{m}$ e comprimento de $5 \mathrm{~m}$, instalada no campo experimental onde o subsolo é composto por uma camada porosa de argila siltosa até a profundidade de 7 $\mathrm{m}$ seguida de uma camada de silte argilo-arenoso até 9 $m$ de profundidade.

A teoria da reação horizontal do solo considera que a reação do solo aos esforços horizontais é proporcional ao deslocamento da estaca. Essa reação horizontal do solo caracteriza o solo em contato com a estaca como um sistema de molas independentes. Desse modo, objetivou-se a determinação do coeficiente de reação horizontal do solo $\left(n_{h}\right)$, definido como a pressão necessária para provocar um deslocamento unitário, tendo dimensões em N/m³.

Logo, os objetivos principais da pesquisa são: determinação do valor de $n_{h}$, obter a capacidade de carga horizontal da estaca e analisar os efeitos da inundação do solo superficial no comportamento da estaca quando submetida a esforços horizontais.

\section{Resultados e Discussão}

Do ensaio de campo, foi possível obter o diagrama de carga vs deslocamento. Através desse diagrama e da equação proposta por Matlock \& Reese, foi possível obter o valor do $n_{h}$ em função do deslocamento horizontal do solo $\left(\mathrm{y}_{0}\right)$. No intuito de obter o valor representativo de $\mathrm{n}_{\mathrm{h}}$ é usual utilizar os valores correspondentes a um intervalo de deslocamento pré-determinado, que para o caso deste trabalho, foi utilizada a proposta de Miguel (1996), que sugere a média dos valores de $n_{h}$ no intervalo de $6 \mathrm{~mm}$ a $12 \mathrm{~mm}$. Desse modo, a tabela a seguir mostra os valores representativos de $n_{h}$ para cada condição do solo, assim como, os deslocamentos horizontais atingidos no ensaio devido à carga máxima aplicada a incrementos lentos.

Tabela 1. Valores obtidos da prova de carga horizontal.

\begin{tabular}{|c|c|c|}
\hline & Solo natural & Solo pré-inundado \\
\hline $\mathrm{n}_{\mathrm{h}}\left(\mathrm{MN} / \mathrm{m}^{3}\right)$ & 14,75 & 8,69 \\
\hline Deslocamento máximo $(\mathrm{mm})$ & 14,10 & 18,98 \\
\hline Carga máxima $(\mathrm{kN})$ & 49 & 40 \\
\hline
\end{tabular}

Com a análise da tabela, pode-se perceber que a préinundação do solo superficial acarretou uma redução de aproximadamente $41 \%$ no valor de $n_{h}$. Essa redução deve-se ao fato do solo do campo experimental ser colapsível, isto é, quando inundado apresenta grande deformação, perda de resistência e, consequentemente, redução da capacidade de carga.

$O$ valor de $n_{h}$ obtido na condição de solo natural $(14,75$ $\mathrm{MN} / \mathrm{m}^{3}$ ) é superior ao valor de $11,9 \mathrm{MN} / \mathrm{m}^{3}$, obtido para uma estaca pré-moldada já ensaiada em outro Campo Experimental da Unicamp, onde 0 solo possui características parecidas (Carvalho et al, 1996).

\section{Conclusões}

Os valores de $n_{h}$ obtidos para as condições de solo natural e pré-inundado demonstram, através da grande diferença entre eles, uma considerável perda da capacidade de suporte da estaca quando o solo é submetido à condição de inundação, evidenciando um comportamento típico de solos colapsíveis.

\section{Agradecimentos}

Ao Prof. Dr. Paulo José Rocha Albuquerque, pela oportunidade de realizar esse projeto, à FAPESP, pelo financiamento da pesquisa e ao $\mathrm{CNPq}$, pela bolsa de iniciação científica.

\footnotetext{
${ }^{1}$ Albuquerque. P. J. R.; Carvalho, D.,Miranda Jr, G.; Zammataro, B. B. Análise de Estacas Escavadas e Hélice Contínua, Carregadas Transversalmente no Topo, em Solo Não Saturado de Diabásio. 2004, São Carlos/SP.

${ }^{2}$ Miguel, M. G.; Belincanta, A.; Costa, C. J. M. e Teixeira, R. S. Provas de Carga Horizontal em Estacas Escavadas a Trado Mecânico em Solo Colapsível da Região de Londrina, Estado do Paraná. 2001, Londrina/PR.

Zammataro, B. B. Comportamento de Estacas Tipo Escavada e Hélice Contínua Submetidas a Esforços Horizontais. 2007, Dissertação (Mestrado em Engenharia Civil), Unicamp/SP, 187p.
} 